\title{
Child road traffic crash injuries at the Red Cross war memorial children's hospital in Cape Town South Africa in 1992, 2002 and 2012
}

Isaac Kihurani

Aga Khan University, isaac.kihurani@aku.edu

Ashley Van Niekerk

University of South Africa

Arjan Bastiaan Van As

Red Cross War Memorial Children's Hospital

Follow this and additional works at: https://ecommons.aku.edu/eastafrica_fhs_mc_paediatr_child_health

Part of the Pediatrics Commons

\section{Recommended Citation}

Kihurani, I., Niekerk, A. V., Van As, A. B. (2014). Child road traffic crash injuries at the Red Cross war memorial children's hospital in Cape Town South Africa in 1992, 2002 and 2012. International Journal of Injury Control and Safety Promotion, 1-7.

Available at: https://ecommons.aku.edu/eastafrica_fhs_mc_paediatr_child_health/44 
This article was downloaded by: [INASP - Kenya]

On: 07 April 2015, At: 02:14

Publisher: Taylor \& Francis

Informa Ltd Registered in England and Wales Registered Number: 1072954 Registered office: Mortimer House, 37-41 Mortimer Street, London W1T 3J H, UK
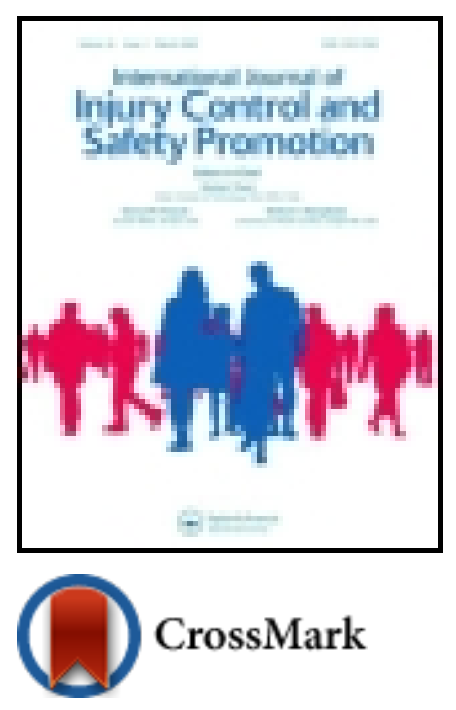

$\underline{\text { Click for updates }}$

\section{International J ournal of Injury Control and Safety Promotion}

Publication details, including instructions for authors and subscription information: http:// www.tandfonline.com/loi/ nics20

\section{Child road traffic crash injuries at the Red Cross War Memorial Children's Hospital in Cape Town, South Africa in 1992, 2002 and 2012}

\author{
Kihurani N. Isaac ${ }^{a}$, Ashley Van Niekerk ${ }^{b} \&$ Arjan Bastiaan Van $A s^{a}$ \\ ${ }^{a}$ Childsafe South Africa and Department of Pediatric Surgery, Red Cross War Memorial \\ Children's Hospital, Klipfontein Road, Rondebosch, 7701 Cape Town, South Africa \\ ${ }^{b}$ Medical Research Council-University of South Africa Safety and Peace Promotion Research \\ Unit; and Institute for Social and Health Sciences, University of South Africa, PO Box 19070, \\ Tygerberg 7505, Cape Town, South Africa \\ Published online: 04 J un 2014.
}

To cite this article: Kihurani N. Isaac, Ashley Van Niekerk \& Arjan Bastiaan Van As (2014): Child road traffic crash injuries at the Red Cross War Memorial Children's Hospital in Cape Town, South Africa in 1992, 2002 and 2012, International J ournal of Inj ury Control and Safety Promotion, DOI: 10.1080/17457300.2014.912236

To link to this article: http:// dx. doi.org/ 10.1080/17457300.2014.912236

PLEASE SCROLL DOWN FOR ARTICLE

Taylor \& Francis makes every effort to ensure the accuracy of all the information (the "Content") contained in the publications on our platform. However, Taylor \& Francis, our agents, and our licensors make no representations or warranties whatsoever as to the accuracy, completeness, or suitability for any purpose of the Content. Any opinions and views expressed in this publication are the opinions and views of the authors, and are not the views of or endorsed by Taylor \& Francis. The accuracy of the Content should not be relied upon and should be independently verified with primary sources of information. Taylor and Francis shall not be liable for any losses, actions, claims, proceedings, demands, costs, expenses, damages, and other liabilities whatsoever or howsoever caused arising directly or indirectly in connection with, in relation to or arising out of the use of the Content.

This article may be used for research, teaching, and private study purposes. Any substantial or systematic reproduction, redistribution, reselling, loan, sub-licensing, systematic supply, or distribution in any form to anyone is expressly forbidden. Terms \& Conditions of access and use can be found at http:// www.tandfonline.com/page/terms-and-conditions 


\title{
Child road traffic crash injuries at the Red Cross War Memorial Children's Hospital in Cape Town, South Africa in 1992, 2002 and 2012
}

\author{
Kihurani N. Isaac ${ }^{\mathrm{a}}$, Ashley Van Niekerk ${ }^{\mathrm{b}}$ and Arjan Bastiaan Van As ${ }^{\mathrm{a} *}$ \\ ${ }^{a}$ Childsafe South Africa and Department of Pediatric Surgery, Red Cross War Memorial Children's Hospital, Klipfontein Road, \\ Rondebosch, 7701 Cape Town, South Africa; ${ }^{b}$ Medical Research Council-University of South Africa Safety and Peace \\ Promotion Research Unit; and Institute for Social and Health Sciences, University of South Africa, PO Box 19070, Tygerberg 7505, \\ Cape Town, South Africa
}

(Received 2 September 2013; final version received 25 March 2014)

\begin{abstract}
Road traffic crashes are a significant cause of the disease burden among children, with the highest mortality in low- and middle-income countries. This observational study explores such injuries in Cape Town, South Africa through an analysis of data for cases in 1992, 2002 and 2012 at the Red Cross War Memorial Children's Hospital, a referral paediatric hospital for children younger than 13 years. Descriptive and time trend analysis of demographic data as well as of the causes, severity and place of injury was conducted. Logistic regression and generalised linear models described factors influencing hospital admission. In the years 1992, 2002 and 2012, a total of 4690 patients presented with injuries sustained as a result of a road traffic crash. Nearly $50 \%(n=2201)$ of them were between five and nine years of age, with 1.7 males for every female. Three-quarters of those who got injured were pedestrians while the second most commonly injured ones were unrestrained passengers. The majority had minor injuries $(58 \%)$, but with notably higher proportions with moderate to severe injuries in the years 2002 and 2012. Forty per cent were admitted for inpatient treatment, with the highest proportion (50\%) in 2002. Admission was related to mechanism and severity. The epidemiological factors assessed remain largely unchanged over the assessment points calling into question the impact of local safety strategies.
\end{abstract}

Keywords: child traffic injury; trauma surveillance; South Africa

\section{Introduction}

Road traffic crash (RTC) injuries are a significant contributor to the disease burden among children. The World Health Organisation (WHO) Global Burden of Disease project estimates that there were 1.3 million deaths worldwide due to RTCs in 2010 (Lozano et al., 2013; WHO, 2013). This represented a $46 \%$ rise in deaths due to RTCs compared with two decades ago (Lozano et al., 2013). A further 50 million were injured or disabled. Whereas a downward trend in the number of road traffic fatalities and injuries over the last couple of decades has been observed in several high income countries, the rest of the globe has seen worsening trends (WHO, 2008a). Road traffic injuries are predicted to be the fifth leading cause of death worldwide by the year 2030 (Hyder, Labinjo, \& Muzafar, 2006; Peden et al., 2008) with Africa amongst several regions expected to see a significant increase in injuries.

Globally, $21 \%$ of road traffic deaths occur among children (Hyder et al., 2006; Peden et al., 2008). Road traffic injuries are the second leading cause of death amongst children aged 5-14 years (Peden et al., 2008). The road traffic mortality rate amongst children globally is estimated at 10.7 per 100,000 population (Lozano et al., 2013; WHO, 2008b). Ninety three per cent of these fatalities occur in low-income and middle-income countries (LMICs) with the highest rates among children in the African, Eastern and Mediterranean regions (WHO, 2008a; WHO, 2006). The road traffic mortality rate amongst children in the African region is estimated at 19.9 per 100,000 population (Peden et al., 2008). In South Africa the road traffic mortality rate overall in 2011 was 33.2 per 100,000 population (Road Traffic Report, 2011). RTCs are one of the leading causes of child injury deaths in South Africa (Burrows, Van Niekerk, \& Laflamme, 2010). In Cape Town, South Africa, road traffic injuries are the leading cause of death in children aged 5-14 years, significantly above HIV/AIDS mortality rates (Groenewald et al., 2008).

LMICs exhibit a disproportionately higher burden of RTC injuries and deaths, but have a relative lack of analytical research on their determinants, in comparison with high-income countries (Hofman, Primack, Keusch, \& Hrynkow, 2005). Consequently, efforts on injury control and prevention are well below the levels directed at other health problems in many of these LMICs (Chan,

*Corresponding author. Email: Sebastian.vanas@uct.ac.za 
Kazatchkine, \& Lob-Levyt, 2010), with very few road safety interventions implemented and evaluated for child safety specifically (Arendse, Swart, Van Niekerk, \& Van As, 2012). Understanding the distribution of the risks of road traffic mortalities and injuries is fundamental to improving road safety, especially in these LMICs.

Despite national recognition of the child road traffic injury burden in South Africa, a middle income level country, there appears to have been an inadequate preventative response by existing networks, programmes and projects (Arendse et al., 2012). This is evidenced by the road traffic mortality rate trends in the country which remain significantly high (Norman, Matzopoulos, Groenewald, \& Bradshaw, 2007; Statistics South Africa, 2009). To appropriately inform targeted prevention strategies for improving child road safety, studies are needed that describe changing patterns in the epidemiology of child road traffic injuries over time. Such studies are required to strengthen the evidence needed to persuade policy makers to adequately provide road traffic injury prevention measures particularly as they affect children. This study aims to describe and analyse the trends in paediatric RTC injuries in Cape Town, South Africa in 1992, 2002 and 2012 using hospital-based trauma surveillance records, and the child and RTC characteristics that are related to trauma unit presentation and further inpatient treatment.

\section{Methods}

The study was approved by the Human Research Ethics Committee of the University of Cape Town's Faculty of Health Sciences (Reference: 401/2011). The study analysed retrospective data captured in Childsafe South Africa's trauma surveillance system based on data captured at the Red Cross War Memorial Children's Hospital $(\mathrm{RCCH})$. The $\mathrm{RCCH}$ is a referral paediatric hospital for children younger than 13 years of age in Cape Town, South Africa. The RCCH is a public institution that serves its immediate environs, and with other public and private institutions, the greater Cape Town. The RCCH is however the only specialised tertiary paediatric hospital in Cape Town, and provides 24-hour casualty, surgical and subspeciality services. Childsafe South Africa is a nongovernmental organisation that maintains a surveillance system for all injured children admitted to RCCH's trauma unit. The surveillance system is one of the few systematic sources of childhood injury data in South Africa. This study included all children with RTC related injury captured in the trauma surveillance system in the years 1992, 2002 and 2012.

The data analysed included the patient's age, gender, cause of injury, place of occurrence, severity of injury and disposition from the trauma unit. Data on the causes of RTC injury included the following mechanisms: "passenger", "MVA pick-up (also known as a 'bakkie' or minibus in
South Africa) passenger", "cycle", "motorcycle" and "other causes". The severity of injury was established using RCCH's four-point Abbreviated Injury Score (AIS) of 'mild', 'moderate', 'severe' and 'mortal'. 'Mild' injuries refer to those that require only minor treatment and usually result in a discharge on the same day of presentation. 'Moderate' injuries are those that require admission, where wounds require suturing or other procedure, all types of fractures, or where the injuries include minor or intermediate head injuries. 'Severe' injuries are those where the patient requires resuscitation or intensive care unit (ICU) care, all poly-traumatised patients, all shocked patients, and those with severe head injuries. 'Mortal' denotes all fatal injuries. The AIS was assigned to each patient by the attending clinician in the trauma unit after they had assessed the child, with all AIS and diagnostic decisions reviewed and finalised by a senior clinician. For disposition, patients were either admitted to $\mathrm{RCCH}$ or discharged from the trauma unit.

The data captured was first entered onto data sheets using Microsoft Excel spreadsheet 2007 (Microsoft Corporation, USA). Data was checked and managed from here both before and after analysis. Data analysis was conducted using STATA 11.0 (StataCorp, 2009). Descriptive analysis was performed for demographic characteristics, mechanisms of injury, place of occurrence, severity of injury and disposition of injured patients. Age was treated as both a continuous and categorical variable. Age groups for children commonly used in literature including under 1 year of age, 1-4 years of age, 5-9 years of age and 10-13 years of age were analysed (Lozano et al., 2013; WHO, 2008b; WHO, 2013). A total of 187 patients (4\%) were excluded from the analysis for age as they either had missing age data $(n=146,3 \%)$ or were older than 13 years of age $(n=41 ; 1 \%)$. The data was analysed in one-year time bins for the years 1992, 2002 and 2012 to evaluate trends in paediatric road traffic injuries over two decades. The Pearson's chi square test was used for dichotomous variables and the $t$-test for continuous variables to assess differences.

The primary outcome was measured in terms of hospital admission. The use of admission rates as a health outcome indicator has been used to gauge the effectiveness of primary and community care, health promotion either in the general population or specific high risk groups, and surgical practice across a multi-levelled health service network. The use of hospital admission as an outcome measure may be affected by a range of factors, including the severity of the condition, patient characteristics such as socio-economic grouping, access to effective referral routes to care, the availability of resources, and the quality of antecedent care delivered (see e.g. Daly, Mason, \& Goldacre, September 2000). In this study we describe paediatric traffic injury admission patterns, and associated factors such as age, gender, mechanism of injury and 
severity of injury which were considered by calculating their risk ratios (RR) in relation to admission. Logistic regression and generalised linear models were used to describe factors associated with admission. A $p$-value of less than 0.05 was considered statistically significant for all statistical analyses.

\section{Results}

In the years 1992, 2002 and 2012, a total of 4690 patients with RTC injuries were presented to RCCH's trauma unit. Of these 2169 (46\%) were presented in 1992, $1224(26 \%)$ in 2002 and $1297(28 \%)$ in 2012.

The mean age of the injured children was $6.3 \pm$ 3.1 years. Nearly $50 \%(n=2201)$ of the injured children were between five to nine years of age. About $2 \%$ $(n=80)$ were less than one year of age. There was no noteworthy change in the age group proportions observed over the years 1992, 2002 and 2012 (Table 1). The proportion of male children was 1.7 times higher than that of the females $(p<0.05)$ with this proportion relatively constant over the two decades. The higher proportion of boys was observed in all the age groups apart from the group of children less than one year of age where the ratio of girls was significantly higher $(1.2 ; p<0.05)$. The leading cause of road traffic injury amongst children at $\mathrm{RCCH}$ over the two decades was MVA pedestrian crashes. Nearly three-quarters of all the children injured were pedestrians ( $n=3306,71 \%)$. Those children travelling as unrestrained motor vehicle passengers were the second most commonly injured in RTCs $(n=498,11 \%)$ (see Figure 1$)$.

The proportion of pedestrian and unrestrained MVA passenger related injuries over the years 1992-2012 was relatively constant. However, there was a decreasing trend in the proportion of cycle related injuries observed over the years 1992-2012. When explored further with respect to age groups, pedestrian crashes remained the most commonly observed mechanism of injury in all the age groups (Figure 2). Unrestrained passenger crash injuries were however more common in those children below one year of age $(n=28,35 \%)$. In those aged between 10 and

Table 1. Demographic data of children with road traffic crash injuries at Red Cross War Memorial Children's Hospital, Cape Town, South Africa in the years 1992, 2002 and 2012.

\begin{tabular}{|c|c|c|c|c|c|c|}
\hline & \multicolumn{2}{|c|}{1992} & \multicolumn{2}{|c|}{2002} & \multicolumn{2}{|c|}{2012} \\
\hline & Number & Per cent & Number & Per cent & Number & Per cent \\
\hline \multicolumn{7}{|c|}{ Age } \\
\hline $0-4$ years & 725 & $36 \%$ & 441 & $37 \%$ & 468 & $37 \%$ \\
\hline $5-9$ years & 998 & $49 \%$ & 558 & $46 \%$ & 645 & $50 \%$ \\
\hline $10-13$ years & 298 & $15 \%$ & 200 & $17 \%$ & 170 & $13 \%$ \\
\hline \multicolumn{7}{|c|}{ Gender } \\
\hline Male & 1354 & $62 \%$ & 783 & $64 \%$ & 821 & $64 \%$ \\
\hline Female & 815 & $38 \%$ & 438 & $36 \%$ & 470 & $36 \%$ \\
\hline \multicolumn{7}{|c|}{ Mechanism of injury } \\
\hline Pedestrians & 1482 & $68 \%$ & 897 & $73 \%$ & 927 & $71 \%$ \\
\hline Unrestrained passengers & 232 & $11 \%$ & 114 & $9 \%$ & 152 & $12 \%$ \\
\hline Restrained passengers & 67 & $3 \%$ & 57 & $5 \%$ & 59 & $5 \%$ \\
\hline Pick-up passengers & 58 & $3 \%$ & 48 & $4 \%$ & 87 & $4 \%$ \\
\hline Cycle & 286 & $13 \%$ & 98 & $8 \%$ & 52 & $4 \%$ \\
\hline Motor cycle & 11 & $1 \%$ & 0 & $0 \%$ & 10 & $1 \%$ \\
\hline Other & 33 & $2 \%$ & 10 & $1 \%$ & 10 & $1 \%$ \\
\hline \multicolumn{7}{|c|}{ Place of occurrence } \\
\hline Road/Pavement & 1838 & $86 \%$ & 828 & $68 \%$ & 910 & $70 \%$ \\
\hline Own home outside & 162 & $8 \%$ & 226 & $18 \%$ & 161 & $12 \%$ \\
\hline Other home outside & 49 & $2 \%$ & 45 & $4 \%$ & 24 & $2 \%$ \\
\hline Other & 90 & $4 \%$ & 122 & $10 \%$ & 157 & $16 \%$ \\
\hline \multicolumn{7}{|c|}{ Severity of injury } \\
\hline Minor & 1561 & $72 \%$ & 505 & $42 \%$ & 663 & $51 \%$ \\
\hline Moderate & 532 & $24 \%$ & 643 & $52 \%$ & 543 & $42 \%$ \\
\hline Severe & 68 & $3 \%$ & 65 & $5 \%$ & 79 & $6 \%$ \\
\hline Mortal & 8 & $1 \%$ & 11 & $1 \%$ & 11 & $1 \%$ \\
\hline \multicolumn{7}{|c|}{ Hospital admission } \\
\hline Admitted & 862 & $40 \%$ & 606 & $50 \%$ & 391 & $30 \%$ \\
\hline
\end{tabular}




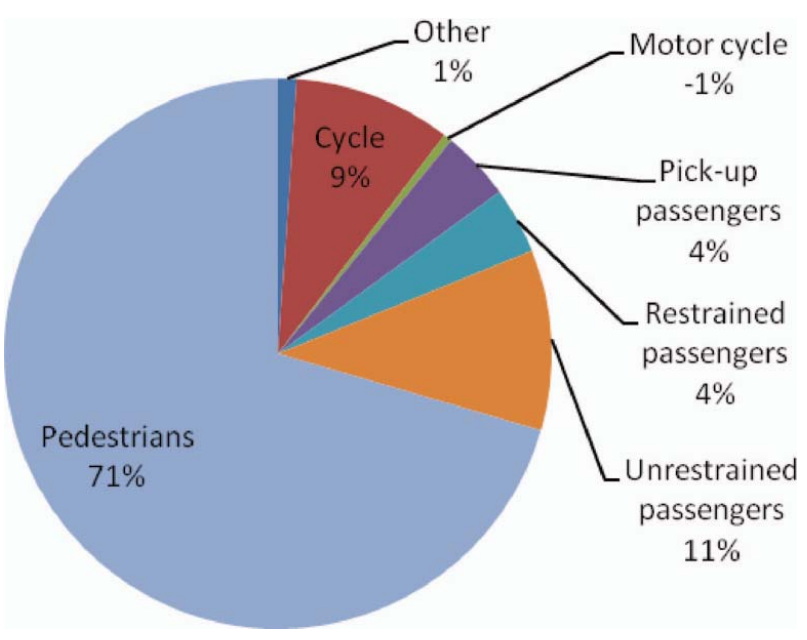

Figure 1. Mechanism of injury in children with road traffic crash injuries at the Red Cross War Memorial Children's Hospital, Cape Town, South Africa, 1992, 2002 and 2012.

13 years, cycle related crashes were the second most common cause of RTC injury $(n=102,15 \%)$.

A substantial proportion of children with RTC injuries at $\mathrm{RCCH}$ were injured immediately outside their own homes $(n=549,12 \%)$, most of them as pedestrians $(n=$ $425,77 \%)$ and cyclists $(n=100,18 \%)$. However, the majority of the rest of the children were injured elsewhere on the roads or pavements $(n=3576,77 \%)$. Most of the latter children were injured as pedestrians $(n=2497$, $70 \%)$, unrestrained vehicle passengers $(n=444,12 \%)$ and cyclists $(n=302,8 \%)$.

According to the AIS index majority of the children with RTC injuries attended to at RCCH had minor injuries $(n=2729,58 \%)$, while $37 \%$ of the children had $(n=$ 1718) moderate injuries and $4 \%(n=212)$ of them suffered from severe injuries. There was a considerably higher proportion of these children with moderate to severe injuries in the years $2002(n=708,58 \%)$ and 2012 $(n=622,48 \%)$ compared with $1992(n=600,28 \%)$. Nearly $80 \%(n=168)$ of those with severe injuries were pedestrians with $10 \%(n=21)$ being unrestrained vehicle passengers. There were 30 deaths reported at the RCCH trauma unit with most of these deaths occurring to pedestrians $(60 \%, n=18)$ and unrestrained vehicle passengers $(20 \%, n=6)$. There was no significant difference observed in the proportion of mortal injuries seen over the years 1992-2012.

Up to $40 \%(n=1859)$ of children who were presented to RCCH with RTC related injuries were admitted to the hospital. Most of the children admitted had moderate injuries $(55 \%, n=1022)$ with $10 \%(n=180)$ having severe injuries and $34 \%(n=635)$ minor injuries according to the AIS index. The proportion of hospital admissions was highest in $2002(50 \%, n=606)$ and lowest in $2012(30 \%$, $n=391)$.

To describe factors that may influence admission related to RTCs in children at RCCH we calculated the RR for age, gender, mechanism of injury and severity of injury (Table 2). The relative risk of admission did not appear to differ significantly with respect to the various age groups and gender (RR 1.04; $p=0.298$ ). Children with pedestrian related injuries had a 2.9 times significantly increased risk of admission when compared with children injured as cyclists (reference group; $p<0.05$ ). The RRs were also significantly increased for children injured as unrestrained and restrained vehicle passengers as well as pick-up or 'bakkie' passengers when compared with cyclists. The risk of admission was 2.56 times for children who sustained moderately severe injuries and 3.65 times for those with severe injuries when compared with those with minor injuries (reference group; $p<0.05$ ).

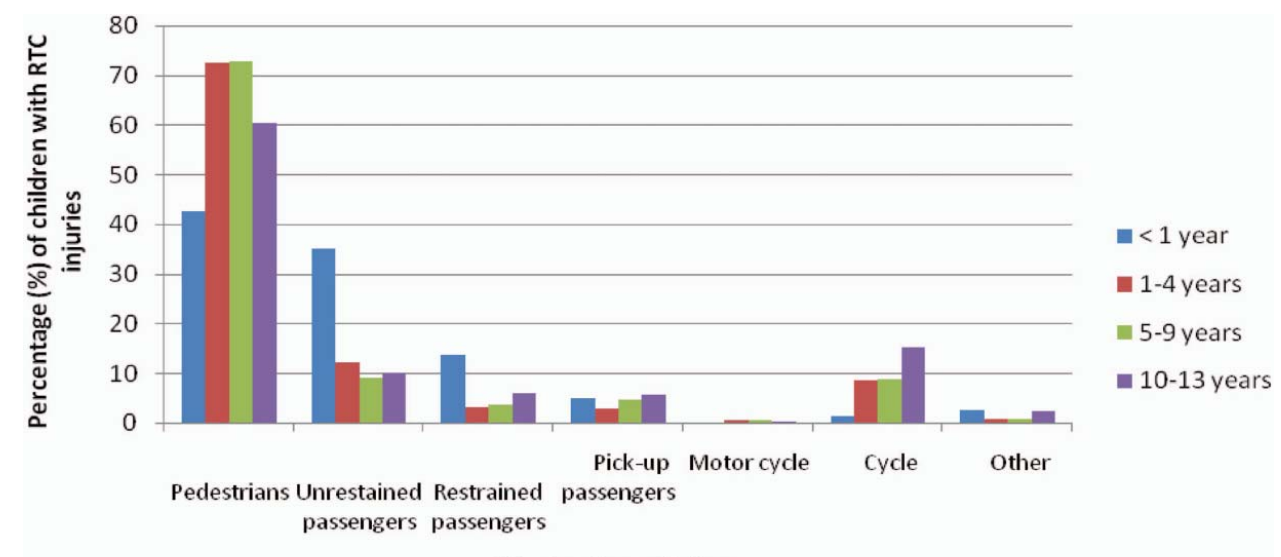

Mechanism of injury

Figure 2. Age group distribution for mechanism of road traffic crash injury in children at the Red Cross War Memorial Children's Hospital, Cape Town, South Africa, 1992, 2002 and 2012. 
Table 2. Factors related to hospital admission in children with road traffic crash injuries at the Red Cross War Memorial Children's Hospital, Cape Town, South Africa, 1992, 2002 and 2012.

\begin{tabular}{lccc}
\hline & Risk Ratio & $p$-Value & {$[95 \% \mathrm{CI}]$} \\
\hline Age: (reference $<1$ year) & & & \\
$\quad$ 1-4 years & 0.86 & 0.25 & $0.66-1.12$ \\
5-9 years & 0.98 & 0.894 & $0.76-1.27$ \\
10-13 years & 0.86 & 0.291 & $0.66-.13$ \\
Gender: (reference male) & & & \\
$\quad$ Sex & 1.04 & 0.298 & $0.97-.12$ \\
Mechanism of injury: (reference cycle) & & \\
Other & 2.33 & $<0.001$ & $1.53-3.56$ \\
Motor cycle & 0.93 & 0.894 & $0.32-2.71$ \\
Pick-up passenger & 1.65 & 0.003 & $1.19-2.29$ \\
Restrained passenger & 2.38 & $<0.001$ & $1.78-3.19$ \\
Unrestrained passenger & 2.34 & $<0.001$ & $1.82-3.00$ \\
Pedestrian & 2.90 & $<0.001$ & $2.32-3.63$ \\
Severity (AIS): (reference minor injuries) & & \\
$\quad$ Moderate & 2.56 & $<0.001$ & $2.36-2.77$ \\
Severe & 3.65 & $<0.001$ & $3.33-3.99$ \\
Mortal & 3.15 & $<0.001$ & $2.51-3.95$ \\
\hline
\end{tabular}

Note: CI: Confidence interval; <: less than; AIS: Abbreviated injury score

\section{Discussion}

Many countries in Sub-Saharan Africa do not have injury surveillance systems that provide reliable data on RTCs and injuries. Indicators, particularly on non-fatal outcomes, are scarce and more so as regards children. Such data provides evidence on the specific etiologies as well as high-risk populations and conditions for RTC injuries. This data contributes to the basis for decision-making and improving treatment and prevention systems currently in use, or establishing simple, cost-effective systems for improving road safety for children. This study sought to provide such data by describing the trends on child road traffic injuries over two decades spanning 1992-2012, from surveillance data in a tertiary referral paediatric hospital for children younger than 13 years of age in Cape Town, South Africa.

This study showed that the mean age for children injured in a RTC and presented to $\mathrm{RCCH}$ in the years 1992, 2002 and 2012 was 6.3 years. The majority of the children were between five to nine years of age with no significant change observed in that age group predominance over the two decades. Other studies have shown that amongst children younger than 15 years, those between five to nine years are at greatest risk of RTC injury and mortality (WHO, 2008a; Road Traffic Report, 2011). In LMICs, the fatal road traffic injury rates are approximately 12.5 per 100,000 children with this rate being much higher than that in high-income countries (WHO, 2008a). Most of these children at that age may be exposed as 'commuters' when they have to get to and from school, particularly if they walk to school, but also as they walk to and from the buses and cars that take them to school (Mabunda, Swart, \& Seedat, 2008). The cognitive processes involved in judgement, decision-making, reasoning and impulse control at that age are rudimentary increasing the vulnerability of children in that age group in the road environment (Giedd, 2004; Zeedyk, Wallace, \& Spry, 2002). The provision of appropriate environmental as well as behavioural interventions may increase road safety for these and other age groups of vulnerable children.

This study also showed the predominance of road traffic injuries amongst males with no significant change in this trend observed over the last two decades. This is similar to trends seen globally where the difference in incidence rates between boys and girls increases with age. Overall, the death rate from road traffic injuries for boys is 13.8 per 100,000 population, compared to a rate for girls of 7.5 per 100,000 population globally (Lozano et al., 2013; WHO, 2008a). This may be explained by risk-seeking behaviour, a significant predictor of involvement in road traffic injury among children and adolescents. Boys have a greater affinity for risk-taking and competitive behaviour, all of which place them at an increased risk of road traffic injury (Waylen \& McKenna, 2002).

Pedestrian RTCs were overwhelmingly the leading mechanism of injury amongst children at $\mathrm{RCCH}$ over the last two decades in this study. Most of these children sustained injuries as pedestrians on the roads or pavements and a significant number, just outside their own homes. Globally, pedestrians form the single largest category of children involved in RTCs. In LMICs, $30 \%-40 \%$ of children who suffer road traffic injuries are pedestrians (Toroyan \& Peden, 2007). Child pedestrian injury is highest in Africa and Asia where it is usual for people to walk along roads (Hyder et al., 2006). In South Africa, pedestrian fatalities comprise a significant share of the traffic injury burden with $33 \%$ of all road traffic deaths involving pedestrians (Road Traffic Report, 2011). In 2010-2011, approximately $20 \%$ of the pedestrian fatalities in South Africa, where age was known, involved children younger than 15 years (Road Traffic Report, 2011). In most of these LMICs, South Africa included, children use roads as 'commuters', for playing, running errands and for conducting small roadside businesses, all of which increase their exposure significantly (Arendse et al., 2012; Bass, Albertyn, \& Melis, 1995; Peden et al., 2008). Targeted environmental and engineering interventions, educational and awareness campaigns, targeted parental supervision, and enforcement are considered optimal for effectively reducing these child pedestrian injuries and risks (Arendse et al., 2012). Given the persistently high incidence of pedestrian related road traffic injuries observed in this study in Cape Town over the last two decades, the existing prevention initiatives probably need reassessment and 
increased effort is needed towards achieving a reduction of RTCs and injuries in that setting.

A significant proportion of children with road traffic injuries at RCCH over the two decades were unrestrained vehicle passengers and indeed this was the second most commonly observed mechanism of road traffic injury in this study. This was particularly significant for those children younger than one year of age. The lack of or improper use of restraints is a major risk factor for injury in young children who are occupants of vehicles in the event of a RTC (Peden et al., 2008). The rate of use of appropriate child restraints in motor vehicles varies considerably across countries with the lowest rates reported in LMICs including South Africa where rates as low as $10 \%$ have been observed (Kling, Nicholls, Ntambeka, \& Van As, 2011). Access or cost issues as well as lack of enforcement remain major impediments to their use in these settings in spite of the overwhelming evidence of their effectiveness in reducing morbidity and mortality from RTCs (Arbogast, Durbin, Cornej, Kallan, \& Winston, 2004; Zaza, Sleet, Thompson, Sosin, \& Bolen, 2001). In South Africa, lower-income families are more likely to drive older vehicles, many of which may not have rear seatbelts, the installation of which is prohibitive. With such families, the free distribution of age-appropriate child restraints combined with education regarding their use has been reported as beneficial (Van Hoving, Sinclair, \& Wallis, 2013). The use of age-appropriate child restraints is however still not compulsory in South African law; in addition, legislation emphasising driver responsibility for passenger restraint use, including those for children, has also been recommended (Van Hoving, Sinclair, \& Wallis, 2013).

Whereas the decreasing trend observed in the incidence of cycle related RTC injuries over the last two decades in this study is commendable, the factors contributing to the decline are not clear. Understanding these factors, if any, may inform prevention or intervention strategies applicable to other mechanisms of injury.

There was a significant decline in this study in the total number of children presenting to RCCH with RTC injuries between 1992 and 2002 onwards. This was related to a new system of health care referrals introduced in the Western Cape region of South Africa that may have impacted the injuries presented to RCCH. In 1997, the GF Jooste Trauma Hospital, located approximately six kilometres from $\mathrm{RCCH}$, opened and the sharp decline in RTC injuries presented to RCCH subsequently should be viewed within that context (Van As \& Rode, 2006). There was also a significant change observed in the severity of RTC injuries presented to RCCH between 1992 and 2002. Up to $58 \%$ of the children who were presented in 2002 had moderate to severe injuries compared with $28 \%$ in 1992 . This may be related to national policy changes that took place in South Africa at about that time seeking to re-structure and strengthen health care sought at primary level facilities while providing timely and appropriate referrals to tertiary hospitals such as RCCH (Van As \& Rode, 2006).

This study showed that up to $40 \%$ of children presented to RCCH with RTC injuries were admitted with the factors influencing admission related to mechanism and severity of injury. This highlights the need to assess both the current hospital referral practices and road safety strategies to ensure the most effective service delivery efforts and appropriate prevention initiatives targeting risk factors described by this study. Particular attention focusing on pedestrians and unrestrained vehicle passengers is warranted.

\section{Strengths and limitations}

This study is based on one of the few systematic sources of childhood traffic injury data in South Africa, an established trauma injury surveillance system housed at the $\mathrm{RCCH}$, and a source of important longitudinal information on child injuries (Van As \& Rode, 2006). The RCCH is the only specialised government paediatric hospital in greater Cape Town. RCCH receives referrals from other health care institutions but most patients present directly. This surveillance system does not track admissions elsewhere in the public health system nor does it include the cases accepted within the private health care system, losses for which there is no estimate available. The RCCH is highly regarded and hence it may be reasonable to assume that many families are likely to seek specialised hospital care there, especially for the more serious injuries, than at other public hospitals.

Despite the limitations to the population coverage in this study we were able to report changing trends in the paediatric traffic injuries that were presented to $\mathrm{RCCH}$, but not the incidence of such injuries for the city or wider region. Population-based data are necessary to determine the extent to which these events impacted the care sought for paediatric traffic injuries. Such studies would be able to describe where care was sought within the health care referral system. This may be of particular relevance as our study showed that $51 \%$ of children in 2012 were discharged from RCCH's causality department and did not require hospital admission. These children may have been treated at primary or secondary health care facilities. Understanding why care was not sought at these levels may promote more effective health care resource allocation (Wesson et al., 2013).

\section{Conclusion}

This study has depicted a decreasing trend in the number of children with RTC injuries presented to RCCH in Cape Town from 1992 to 2012. This has most likely been influenced by the city's changing tertiary hospital system over this period. The study indicates that the age, gender, cause, place and severity of RTC injuries remained largely 
unchanged over the assessment points. This should provide impetus for further studies assessing the impact of road safety strategies currently being utilised in this region and their cost-effectiveness particularly as they affect children. This may inform policy and targeted interventions with the aim of reducing the burden of RTC injuries amongst children in South Africa.

\section{Acknowledgements}

We wish to acknowledge the support provided by Mr Henri Carrara in the statistical analysis of this study.

\section{References}

Arbogast, K.B., Durbin, D.R., Cornej, R.A., Kallan, M.J., \& Winston, F.K. (2004). An evaluation of the effectiveness of forward facing child restraint systems. Accident Analysis and Prevention, 36(4), 585-589.

Arendse, N., Swart, L., Van Niekerk, A., \& Van As, A.B. (2012). Child pedestrian injury prevention responses: Towards prevention priorities for South Africa. In A. Van Niekerk, S. Suffla, \& M. Seedat (Eds.), Crime, violence and injury in South Africa: 21st century solutions for child safety (pp. 23-43). Johannesburg: PsySSA Press.

Bass, D., Albertyn, R., \& Melis, J. (1995). Child pedestrian injuries in the Cape metropolitan area-final results of a hospital-based study. South African Medical Journal, 85(2), 96-99.

Burrows, S., Van Niekerk, A., \& Laflamme, L. (2010). Fatal injuries among urban children in South Africa: Risk distribution and potential for reduction. Bulletin World Health Organization, 88(4), 267-272.

Chan, M., Kazatchkine, M., \& Lob-Levyt, J. (2010). Meeting the demands for results and accountability: A call for action on health data from eight health agencies. PLoS Medicine, 7(1), $1-4$.

Daly, E., Mason, A., \& Goldacre, M.J. (September 2000). Using admission rates as a health outcome indicator: Literature review. Report to the Department of Health. Retrieved February 10, 2014 from http://nchod.uhce.ox.ac.uk/Mortality\% 20Rates\%20Literature.pdf

Giedd, J. (2004). Structural magnetic resonance imaging of the adolescent brain. Annals of the New York Academy of Sciences, 1021, 77-85.

Groenewald, P., Bradshaw, D., Daniels, J., Matzopoulos, R., Bourne, D., Blease, D., ... Naledi, T. (2008). Cause of death and premature mortality in Cape Town, 2001-2006. Tygerberg: South African Medical Research Council.

Hofman, K., Primack, A., Keusch, G., \& Hrynkow, S. (2005). Addressing the growing burden of trauma and injury in lowand middle-income countries. American Journal of Public Health, 95, 13-17.

Hyder, A. A., Labinjo, M., \& Muzafar, S. S. F. (2006). A new challenge to child and adolescent survival in urban Africa: An increasing burden of road traffic injuries. Traffic Injury Prevention, 7, 381-388.
Kling, J., Nicholls, T., Ntambeka, P., \& Van As, A.B. (2011) Restraint use for child passengers in South Africa. South African Medical Journal, 101(3), 146.

Lozano, R., Naghavi, M., Foreman, K., Lim, S., Shibuya, K., Aboyans, V., ... Memish, Z.A. (2013). Global and regional mortality from 235 causes of death for 20 age groups in 1990 and 2010: A systematic analysis for the Global Burden of Disease Study 2010. The Lancet, 380(9859), 2095-2128.

Mabunda, M., Swart, L., \& Seedat, M. (2008) Magnitude and categories of pedestrian fatalities in South Africa. Accident Analysis and Prevention, 40(2), 586-593.

Norman, R., Matzopoulos, R., Groenewald, P., \& Bradshaw, D. (2007). The high burden of injuries in South Africa. Bulletin World Health Organization, 85(9), 695-702.

Peden, M., Oyegbite, K., Ozanne-Smith, J., Hyder, A.A., Branche, C., Rahman, A.F., ... Bartolomeos, K. (2008). World report on child injury prevention. Geneva, Switzerland: World Health Organization.

Road Traffic Report. (2011). Road Traffic Management Corporation, Republic of South Africa. Retrieved from http:/www. arrivealive.co.za

StataCorp. (2009). Stata statistical software: Release 11. cCollege sStation, TX: StataCorp LP.

Statistics South Africa. (2009). Road traffic accident deaths in South Africa, 2001-2006: Evidence from death notification. Pretoria: Statistics South Africa.

Toroyan, T., \& Peden, M. (2007). Youth and road safety. Geneva, Switzerland: World Health Organization.

Van As, A. B., \& Rode, H. (2006). The history of paediatric trauma care in Cape Town. South African Medical Journal, 96, 874-878.

Van Hoving, D.J., Sinclair, M., \& Wallis, L.A. (2013). Patterns of seatbelt use in different socioeconomic communities in the Cape Town Metropole, South Africa. South African Medical Journal, 103(9), 628-631.

Waylen, A., \& McKenna, F. (2002, March). Pre-driver's attitudes towards driving. In 67th Road Safety Congress (pp. 1-12). United Kingdom: The Royal Society for the Prevention of Accidents.

Wesson, H.K.H., Bachani, A.M., Mtambeka, P., Schulman, D., Mavengere, C., Stevens, K.A., ..., Van As, A.B. (2013). Pediatric burn injuries in South Africa: A 15-year analysis of hospital data. Injury, International Journal for the Care of the Injured, 44(11), 1477-1482.

WHO. (2006). The World health report: Working together for health. Geneva, Switzerland: World Health Organization.

WHO. (2008a). The global burden of disease: 2004 update. Geneva, Switzerland: World Health Organization.

WHO. (2008b). World health statistics. Geneva, Switzerland: World Health Organization.

WHO. (2013). Global status report on road safety 2013: Supporting a decade of action. Geneva, Switzerland: World Health Organization.

Zaza, S., Sleet, D.A., Thompson, R. S., Sosin, D. M., \& Bolen, J. C. (2001). Reviews of evidence regarding interventions to increase use of child safety seats. American Journal of Preventive Medicine, 21(4), 31-47.

Zeedyk, M.S., Wallace, L., \& Spry, L. (2002). Stop, look, listen, and think? What young children really do when crossing the road. Accident Analysis \& Prevention, 34(1), 43-50. 